\title{
Prevalence and associations of depression among patients with cardiac diseases in a public health institute in Trinidad and Tobago
}

Mandreker Bahall

\begin{abstract}
Background: Psychosocial issues are major determinants as well as consequences of cardiovascular disease (CVD). This study sought to assess the prevalence and identify factors associated with depression among patients with cardiac disease in a public health institute in Trinidad and Tobago.

Methods: A cross-sectional study was conducted with a convenience sample of 388 hospitalised, stable, adult patients with cardiac disease admitted in the only tertiary public health institute in South Trinidad. Patients were identified and interviewed 3 to 5 days after admission using a questionnaire comprising questions on demographic, medical, and lifestyle issues and the 9-item Patient Health Questionnaire (PHQ-9).

Results: The prevalence of clinically significant depression (PHQ-9 > 9) among hospitalised patients with cardiac disease was 40.0\%. However, the prevalence of non-minimal depression (PHQ-9 $\geq 5$ ) in this study was $78.4 \%$. It was greater among women (83.1\%) than among men (72.9\%). Non-minimal depression was associated with sex $(p=0.015)$, employment status $(p=0.007)$, hypertension $(p=0.017)$, stressful life $(p \leq 0.001)$, feelings of depression $(p \leq 0.001)$, regular exercise ( $p \leq 0.001)$, and living alone $(p=0.006)$. Age, ethnicity, education level, income, or religious affiliations were not associated $(p>0.05)$ with depression. Participants diagnosed with depression commonly reported feeling tired (81.2\%), having trouble sleeping (74.7\%), and moving/speaking slowly (73.5\%). Patients with self-claimed depression (past or current) were four times more likely to have depression and those with self-reported stress and loneliness were twice as likely to have depression. Employed patients and those who exercised regularly were approximately $50 \%$ less likely to have depression.
\end{abstract}

Conclusions: Clinical depression prevalence among hospitalised patients with cardiac disease was 40.0\%. Approximately twice as many (78.4\%) had non-minimal depression, with higher prevalence among women. Employment, sex, hypertension, stressful life, feelings of depression, regular exercise, and living alone were associated with non-minimal depression. Patients with self-claimed depression, stress, and those living alone had a much higher likelihood of having depression, while those who were employed and exercised regularly were approximately half as likely to have depression.

Keywords: CVD risk factors, Depression, Prevalence of depression, Associations of depression, PHQ-9

(c) The Author(s). 2018 Open Access This article is distributed under the terms of the Creative Commons Attribution 4.0 International License (http://creativecommons.org/licenses/by/4.0/), which permits unrestricted use, distribution, and reproduction in any medium, provided you give appropriate credit to the original author(s) and the source, provide a link to the Creative Commons license, and indicate if changes were made. The Creative Commons Public Domain Dedication waiver (http://creativecommons.org/publicdomain/zero/1.0/) applies to the data made available in this article, unless otherwise stated. 


\section{Introduction}

Many patients with cardiac disease feel anxious, worried, and depressed. Depression, defined as a mood disorder that causes a persistent feeling of sadness and loss of interest [1], has moved from the fourth leading cause of disability worldwide in 1996 [2] to the leading cause of disability globally in 2017 according to the World Health Organization [3]. Cardiac disease treatment has nonetheless focused on physical symptoms, such as angina, arrhythmias, and heart failure, and not on psychological complications [4]. Depression can lead to psychological, physical, and social consequences [5]. Psychological effects include anxiety, fear, sadness [6], hopelessness [6], guilt [6], and irritability [6]. Social consequences involve a change in the functionality of a person and may include substance use and abuse [7], social withdrawal [7], and decreased performance in daily activities [7]. The long-term effects of depression have been linked to brain damage [8], negative impact on the heart [9], and reduced physical activity or the development of sedentary lifestyles [10]. Depression influences lifestyle in areas such as smoking, eating, exercising, adjustment to family and social life, and employment $[11,12]$. It is associated with an increase in hospital readmissions [13], increased incidence of heart failure [14], double the long-term risk of death after a heart attack [15], increased mortality risk by twofold $[5,16]$, and decreased quality of life and increased medical morbidity [17]. Depression is also associated with elevated risk of cardiovascular (CVD) [18] and coronary artery disease (CAD). [19]

Accompanying depression on patients with cardiac disease can be more pronounced because of accompanying medical and social factors. Medical factors can be human immune deficiency virus (HIV), cancer, and end-stage renal diseases. Socio-economic status, particularly education and income, may be associated with depression. [20] In addition to these effects, murder (463 recorded in 2016) [21], sexual offences (693 in 2014) [22], rape (159 recorded in 2014) [22], suicide (14.5 per 100,000 in 2015) [23], divorce (2814 in 2015) [24], and unemployment [25] may have a considerable impact on depression. Depression in patients with coronary heart disease (CHD) has a high persistence rate if left untreated [26] and can worsen CVD burden, which is already the leading cause of mortality in Trinidad and Tobago [27] in line with the worldwide data [28].

Studies conducted in Trinidad and Tobago in selected cross-sectional samples have revealed the prevalence of depression to be $12.8 \%$ among adults visiting family physicians [29], 28.3\% among patients with chronic diseases [30], 14.0\% among adolescents [31], and 17.9\% among patients treated for type 2 diabetes mellitus [32]. However, studies on the prevalence of depression among patients with cardiac diseases have not been reported. This study aimed to determine the prevalence and identify factors associated with depression among patients with cardiac diseases admitted for cardiac care to public hospitals in Trinidad and Tobago.

\section{Methods}

The target population consisted of all patients admitted to public hospitals in Trinidad and Tobago for cardiac care. The sampled population however consisted of all patients admitted for cardiac diseases at the San Fernando General Hospital. The San Fernando General Hospital is one of the four hospitals providing tertiary care in Trinidad and Tobago. It is a public, 745-bed facility that serves half the population of Trinidad or approximately 600,000 people. Medical admissions account for a total of approximately 1400 each month [33] of which one-fifth pertains to cardiac disease, mainly unstable angina (IHD), arrhythmias, heart failure, or valvular heart disease. A single institution was selected because of cost considerations, similarity in the conditions among hospitalised patients with cardiac disease, and the large number of patients this particular hospital treats.

\section{Selection of participants}

During the 5-month period from November 1, 2015 to March 31, 2016, all patients admitted to the hospital for cardiac diseases were examined for eligibility for participation in the study. The medical ward admission books were used to identify patients with a cardiac diagnosis. The identified patients with cardiac disease were approached for discussion on the nature of the study and their willingness to grant consent for participation. The eligibility criteria were stable cardiac disease for a minimum of 3 months, age 18 years or older, absence of confusion (ability to understand, think clearly, and produce meaningful understandable statements), and ability to communicate in the native English language for approximately $20 \mathrm{~min}$ and recall experiences without difficulty. The exclusion criteria were severe cardiac illness (i.e. patients who are unstable, very short of breath, or exhausted), and accompanying major debilitating comorbidities such as dialysis, terminal stage of cancer (cancer that has spread to various parts of the body), acquired immune deficiency syndrome (AIDS) (i.e. patients who were symptomatic: weak, emaciated, and likely to have opportunistic infections), or stage $1 \mathrm{~V}$ heart failure (i.e. patients who were very symptomatic at rest or minimal exertion). Medical students acted as research assistants and were trained on the identification of patients with cardiac disease, the conduction of interviews, and the collection of data. Through convenience sampling, patients with cardiac disease, identified from the patient records and whose diagnoses were confirmed by the treating physicians, were selected for possible participation in the study. 
Potential participants were briefed on the nature of study, and their willingness to participate was ascertained. They were also informed of their rights (freedom of choice to participate, discontinue, or refuse to participate). Patients whose verbal consent was acquired were interviewed. Interviews were stopped and resumed if the interviewees were in the meantime needed for medical examinations, consultations, or investigations. Face to face interviews were conducted at the patient's bedside 3 to 5 days after admission. This would allow time for patient stabilisation and would avoid interference with medical interventions. Since the average length of stay for medical patients, including those with cardiac diseases, is 5.6 days, most patients were available for interview 3 days after admission. A sample size of 388 was determined to be sufficient using a $5 \%$ margin of error and a prevalence of $50 \%$ in the population.

\section{Data collection instrument}

The data collection instrument was a questionnaire that contained survey items related to patient demographics and a depression diagnostic tool. Data collected included socio-demographic variables (age, sex, height, weight, ethnicity, level of education (primary, secondary, or tertiary), current employment status, and religion), self-reported medical and lifestyle history (hypercholesterolemia, current smoking (i.e. smoking up to within 30 days of the interview), diabetes mellitus, hypertension, abdominal obesity, stressful life, depression, daily consumption of substantial fruits and vegetables, exercise (at least 3 times per week for $20 \mathrm{~min}$ ), regular alcohol consumption, and family history of ischaemic heart disease (female parent or siblings younger than 65 years old and male parent or siblings younger than 55 years old reported to have or treated for heart disease)), other medical history (chronic obstructive pulmonary disease, cancer, end-stage renal disease, peripheral vascular disease, stroke/transient ischaemic attack, and psychosis), specialised examinations/ treatment (angiography, angioplasty, and coronary artery bypass grafting), and others such as social support (source of support and care). Patients were guided on the interpretation of social support (receiving the required help in daily chores), of exercise (exercising regularly for $20 \mathrm{~min}$ at least 3 times per week), feeling stressed - anxious, irritable, and depressed - 'down', sad, or dejected. The type and duration of cardiac disease were also recorded.

The PHQ-9 was selected to measure depression among the commonly used instruments. The PHQ-9 has been widely used among patients with cardiac disease with good sensitivity and specificity and it is easy to administer. A cut-off score of $\geq 5$ for minor depression had sensitivity of 0.91 and specificity of 0.81 for a Sri Lankan population [34]. The PHQ- 9 has a sensitivity of $54 \%$ and specificity of $90 \%$ for scores $\geq 10$ in a United States and Canada population [35]. Overall, the PHQ-9 was reported to have $94 \%$ sensitivity and $84 \%$ specificity for scores $>8$ and achieved greater accuracy than the depression component of the Hospital Anxiety and Depression score (cut-off of 5, sensitivity $=81 \%$; specificity $=77 \%$ ) [36]. The PHQ-9 comprises nine questions: 'little interest or pleasure in doing things,' 'feeling down, depressed, or hopeless,' 'trouble falling or staying asleep or sleeping too much,' 'feeling tired or having little energy', 'poor appetite or overeating, 'feeling bad about yourself or that you are a failure or have let yourself or your family down', 'trouble concentrating on things such as reading the newspaper or watching television', 'moving or speaking so slowly that other people could have noticed or the opposite - being so fidgety or restless that you have been moving around a lot more than usual', and 'thoughts that you would be better off dead or of hurting yourself in some way'. The questions are scored using a scale of 0 to 3: not at all (0), several days (1), more than half the days (2), and nearly every day (3). The PHQ-9 scores classify depression as mild (score: $5-9)$, moderate (10-14), moderately severe (15-19), and severe (20-27) [37]. While most studies have used a score signifying higher than moderate depression as warranting intervention, even mild depression should be identified because of its role in worsening CAD. A study with hospitalised patients with cardiac disease utilised depression with a cut-off of 5 or non-minimal depression (PHQ-9 $\geq 5$ ) [38] to determine depression prevalence. In this study, tests of association and strength of association were conducted utilising PHQ-9 $\geq 5$. For this, depression scores were dichotomised into less than mild depression (PHQ-9 $<5$ ) or depression (PHQ-9 $\geq 5$ ). In addition, a significant clinical depression score (PHQ-9 $>9$ ) was calculated to compare the prevalence among various studies, since most of these used a cut-off for depression of PHQ-9 $>9$.

\section{Statistical analysis}

Data collected were entered and stored in a password-secured computer. SPSS, Version 21 (IBM Corp., Armonk, NY) was used to analyse the data through both descriptive and inferential statistical methods. Descriptive methods included frequency and percentage distributions tables, bar graphs, and summary statistics. Inferential methods included forming 95\% confidence intervals (CIs), and chi-square tests of association as was required for this cross-sectional study. Odds ratios as opposed to relative risks were used to determine the strength of the associations, since the cross-sectional sample had a high prevalence of depression [39].

Ethical approval was granted by the ethics committee of the South West Regional Authority on October 21, 2015. 


\section{Results}

Of the 396 patients identified as being eligible for participation in the study during the period from November 1, 2015 to March 31, 2016, 388 (98.0\%) provided verbal consent and eight (2.0\%) refused (Fig. 1). The reliability (Cronbach's alpha) of the questionnaire was 0.747 and the reliability (Cronbach's alpha) of the PHQ-9 was 0.749, which exceed the minimum acceptable of 0.70 [40]. Patients were predominantly female $(n=207 ; 53.4 \%)$, aged 45-74 years $(n=268 ; 69.1 \%)$, of Indo-Trinidadian descent $(n=280 ; 72.2 \%)$, had at most a primary school education ( $n=232 ; 59.8 \%$ ), and had a monthly income of less than TT\$5000 ( $n=232 ; 59.8 \%)$. Table 1 . The highest prevalent comorbidity was hypertension $(84.5 \%)$ followed by diabetes (65.7\%) (Fig. 2). The most common cardiac disease was ischaemic heart disease or coronary heart disease (75\%), followed by cardiomyopathy $(7.2 \%)$, valvular heart disease $(3.1 \%)$, cardiac arrhythmia (4.1\%) and heart failure (4.6\%). Approximately half (53.9\%) of the patients reported a history of self-claimed stressful life prior to diagnosis and a high percentage (42.3\%) also had a history of self-claimed depression (Fig. 3). Smoking and alcohol use were not common among participants.

The prevalence of each of the nine PHQ-9 depression scale indicators was: feeling tired (88.5\%), having trouble sleeping (85.6\%), moving/speaking slowly (83.9\%), feeling down, depressed, hopeless (70.5\%), poor appetite/overeating (66.8\%), trouble concentrating (61.8\%), little interest/pleasure in doing anything (56,6\%), feeling bad about self/failure/let family down (42.1\%), and thoughts of being better off dead/self-harm (14.1\%).

Depression prevalence or significant clinical depression based on PHQ $>$ 9, i.e. at least moderate depression, was $40.2 \%$. However, further analyses used depression based on non-minimal depression (PHQ-9 score $\geq 5$ ), which was present in 78.4\% [ $n=304 ; 95 \%$ CI $(73.9,82.3)]$ (Fig. 4). Non-minimal depression (PHQ-9 score $\geq 5$ ) was associated with a number of demographic and lifestyle variables and comorbidities such as sex $(p=0.015)$, employment $(p=0.007)$, hypertension $(p=0.017)$, previous stressful life $(p \leq 0.001)$, current stressful life $(p=0.001)$, previous feelings of depression ( $\mathrm{p} \leq 0.001)$, current feelings of depression $(\mathrm{p} \leq 0.001)$, regular exercise $(\mathrm{p} \leq 0.001)$, and loneliness $(\mathrm{p} \leq 0.001)$. However, depression was independent of ethnicity $(p=0.090)$, education level $(p=0.209)$, religion $(p=0.689)$, and diabetes mellitus $(p=0.061)$.

Table 2 presents the odds ratios of non-minimal depression for significantly associated comorbidities, psychological, lifestyle, and CVD complications, measured with the associated 95\% CIs, and the corresponding $p$-values. The participants of male sex [OR: 0.548; $p=0.015 ;$ CI $(0.336,0.894)]$, those who were employed [OR: $0.452 ; p=0.007$; CI $(0.252,0.811)$, and those who exercised at least three times per week [OR: 0.394; $p=0.001 ; \mathrm{CI}(0.241,0.645)]$ were approximately $50 \%$ less likely to be depressed. However patients with hypertension [odds ratio (OR): $2.063 ; p=0.017 ; 95 \%$ CI $(1.129$, $3.767)$ ], current stressful lifestyle [OR: $2.943 ; p=0.001 ; 95 \%$

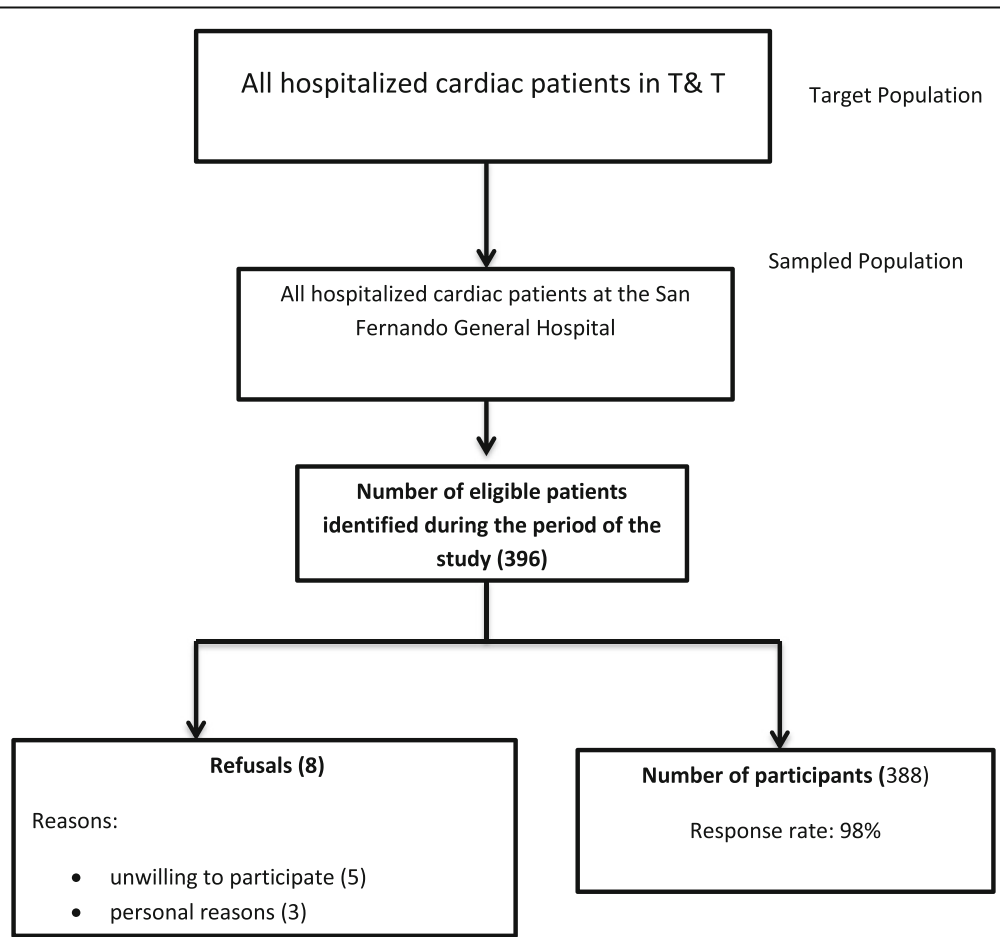

Fig. 1 Selection of study participants 
Table 1 Frequency distribution of socio-demographic variables

\begin{tabular}{|c|c|c|}
\hline Variable & $n$ & $\%$ \\
\hline \multicolumn{3}{|l|}{ Sex } \\
\hline Male & 181 & 46.6 \\
\hline Female & 207 & 53.4 \\
\hline \multicolumn{3}{|l|}{ Age group } \\
\hline$<35$ & 11 & 2.8 \\
\hline $35-44$ & 24 & 6.2 \\
\hline $45-54$ & 50 & 12.9 \\
\hline $55-64$ & 97 & 25.0 \\
\hline $65-74$ & 121 & 31.2 \\
\hline $75-84$ & 66 & 17.0 \\
\hline 85 \& over & 19 & 4.9 \\
\hline \multicolumn{3}{|l|}{ Ethnicity } \\
\hline Indo-Trinidadian & 280 & 72.2 \\
\hline Afro-Trinidadian & 83 & 21.4 \\
\hline Mixed & 25 & 6.4 \\
\hline \multicolumn{3}{|l|}{ Education } \\
\hline Less than primary & 34 & 8.8 \\
\hline Up to Primary & 232 & 59.8 \\
\hline Secondary & 99 & 25.5 \\
\hline Tertiary & 23 & 5.9 \\
\hline \multicolumn{3}{|l|}{ Monthly income \$TT) } \\
\hline$<25,000$ & 70 & 18 \\
\hline $2501-5000$ & 232 & 59.8 \\
\hline $5001-10,000$ & 26 & 6.7 \\
\hline Over 10,000 & 11 & 2.8 \\
\hline \multicolumn{3}{|l|}{ Religion } \\
\hline Islam & 25 & 6.4 \\
\hline Hindu & 157 & 40.5 \\
\hline Christian & 201 & 51.8 \\
\hline Other & 5 & 1.3 \\
\hline \multicolumn{3}{|l|}{ Religiosity } \\
\hline Extremely religious & 42 & 10.8 \\
\hline Very religious & 217 & 55.9 \\
\hline Somewhat religious & 112 & 28.9 \\
\hline Not religious & 17 & 4.4 \\
\hline
\end{tabular}

CI $(1.771,4.892)]$, previous stressful lifestyle [OR: 2.327; $p=0.001$; CI $(1.417,3.822)]$, current feelings of depression [OR: $6.724 ; p=0.001 ; 95 \% \mathrm{CI}(3.432,13.175)]$, previous feelings of depression [OR: $5.517 ; p=0.001$; CI $(2.815$, 10.813)], and loneliness [OR: 2.992; $p=0.006$; CI (1.316, 6.798)] were more likely to be depressed. (Table 2).

\section{Discussion}

The prevalence of clinically significant depression, i.e. at least moderate depression (PHQ $>9)$, was 40.0\% ( $n=$
155) for patients with cardiac disease commonly due to IHD, arrhythmias, and valvular heart disease. Varying depression prevalence has been found in other studies: $45.1 \%$ among patients with IHD [41] and 22\% among those with cardiovascular disease [42], 14\% for valvular heart disease [42], and $29 \%$ for arrhythmia without structural heart disease [42]. Studies by the American Psychiatric Association reported high prevalence of depression in patients with CAD [43]. Based on the PHQ-9, Haddad et al. found that $13.6 \%$ of patients with CHD (including those with a history of myocardial infarction (MI), angina, or those that had undergone coronary artery revascularisation procedures) were depressed [36]. Another study with patients with post-acute MI using the PHQ- 9 found that $18.7 \%$ of patients met the PHQ-9 criteria for depression [44]. Polikandrioti et al. found that 17.4 and $24.2 \%$ of hospitalised patients with heart failure had minor and major depression, respectively [45]. Such variations may result from the differences in the composition of the samples in these studies or accompanying confounding factors. Depression prevalence was found to be higher among younger women $[46,47]$ and in patients with post-acute MI aged 65 years and older [48]. In the case of Trinidad and Tobago clinical depression may be high because of other confounding factors such as accompanying comorbid conditions and social determinants such as crime, disputes, traffic congestion, and economic issues.

The most common depressive symptoms experienced by patients in the last 2 weeks as reported in our study were feeling tired/having little energy $(88.5 \%)$, moving or speaking slowly/fidgety, restless (83.8\%), trouble falling asleep/staying asleep/too much sleep (83.5\%), and feeling down, depressed, and hopeless (70.3\%), in line with the results reported by Rohyans et al. who found that the most frequently reported depressive symptom by the patients on a scale from 0 (not at all) to 3 (nearly every day) was "feeling tired/no energy" with $69 \%$ of patients reporting a score of 3 (mean $=2.6)$ [49]. The next most frequently reported depressive symptom according to Rohyans et al. was "trouble falling or staying asleep" with $43 \%$ of patients reporting a score of $3($ mean $=2.0)$ [49]. Whooley et al. revealed depressive symptoms in $19.6 \%$ of patients with CVD [50]. However, among patients with CAD, the prevalence of major depressive disorder or experiences of an elevation in depressive symptoms was $20-40 \%$ [51]. The specific symptoms experienced by patients after admission may be related to the consequential effects of the cardiac condition [52]. In fact, mild depression may be a reflection of the somatic items on the PHQ-9. This somatic effect may be dampened, however, a few days after admission when the patient's physical condition has improved. In addition, patients reported on their experience in the 2 weeks prior to interview. 


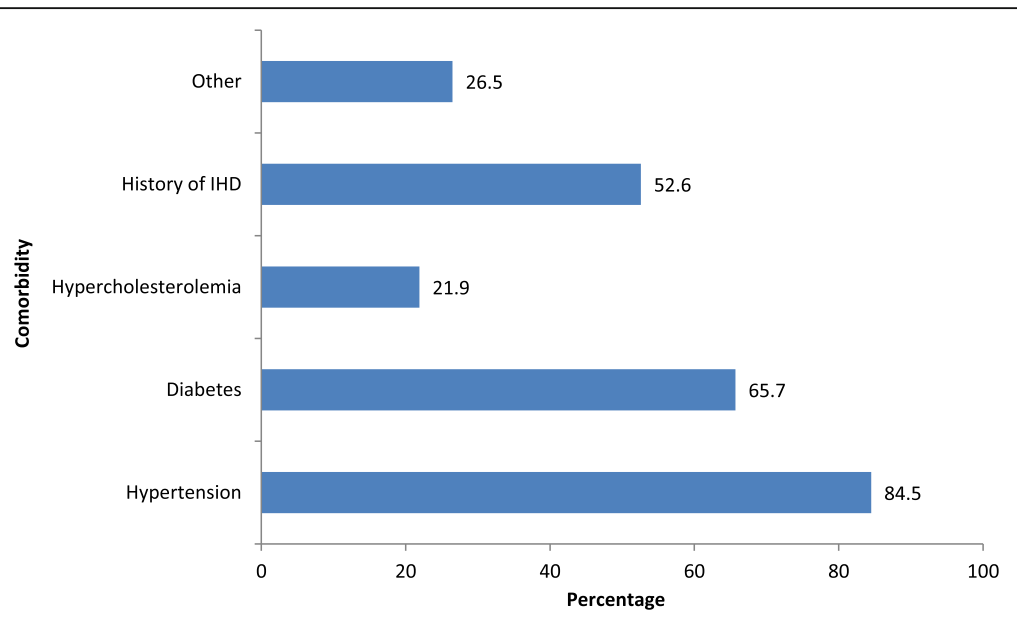

Fig. 2 Patients' cardiovascular disease comorbidities

In this study, the commonest risk factors were hypertension followed by diabetes mellitus, stressful life, and family history of IHD, with clinical depression ranking fifth. Furthermore, diabetes, hypertension, hypercholesterolemia, abdominal obesity, end-stage renal disease, cancer, and chronic obstructive pulmonary disease accompanying a cardiac problem were associated with increased levels of depression compared to the absence of these conditions. Multiple chronic conditions such as diabetes, heart disease, and arthritis are associated with significantly higher levels of depressive symptoms [53] as reported by other studies. Higher levels of depression were also found in patients with more health conditions [54] and those with chronic diseases and other non-cardiac medical illnesses [55].

Apart from clinical depression discussed above, the study also analysed the effect of non-minimal depression (PHQ-9 $\geq 5$ ), which had a prevalence of 78.4\% $(n=304)$. Although most studies define depression as moderate to severe depression, it may be useful to also examine non-minimal depression because, when ignored, it may have negative consequences. These patients may worsen psychologically and physically. Furthermore, mild depression may benefit from some form of intervention or monitoring.

\section{Associations and predictors}

Age showed no association with non-minimal depression (PHQ-9 $\geq 5$ ) in this study. This study also found no significant association with diabetes mellitus and non-minimal depression. This was unexpected. Increased depression among diabetics was identified by Anderson et al. who found that in controlled studies, the odds of depression in the diabetic group were twice as high as those in the non-diabetic comparison group $(\mathrm{OR}=2.0,95 \%$ CI $1.8-2.2)$ [56]. Al-Ghamdi et al. also concluded that depression is more common among diabetics (34\%) than among non-diabetics $(13 \%, p<0.001)$ [57].

In this study, patients who had undergone open heart surgery intervention experienced more depression $(83.3 \%, p=0.49)$, than did those who had undergone

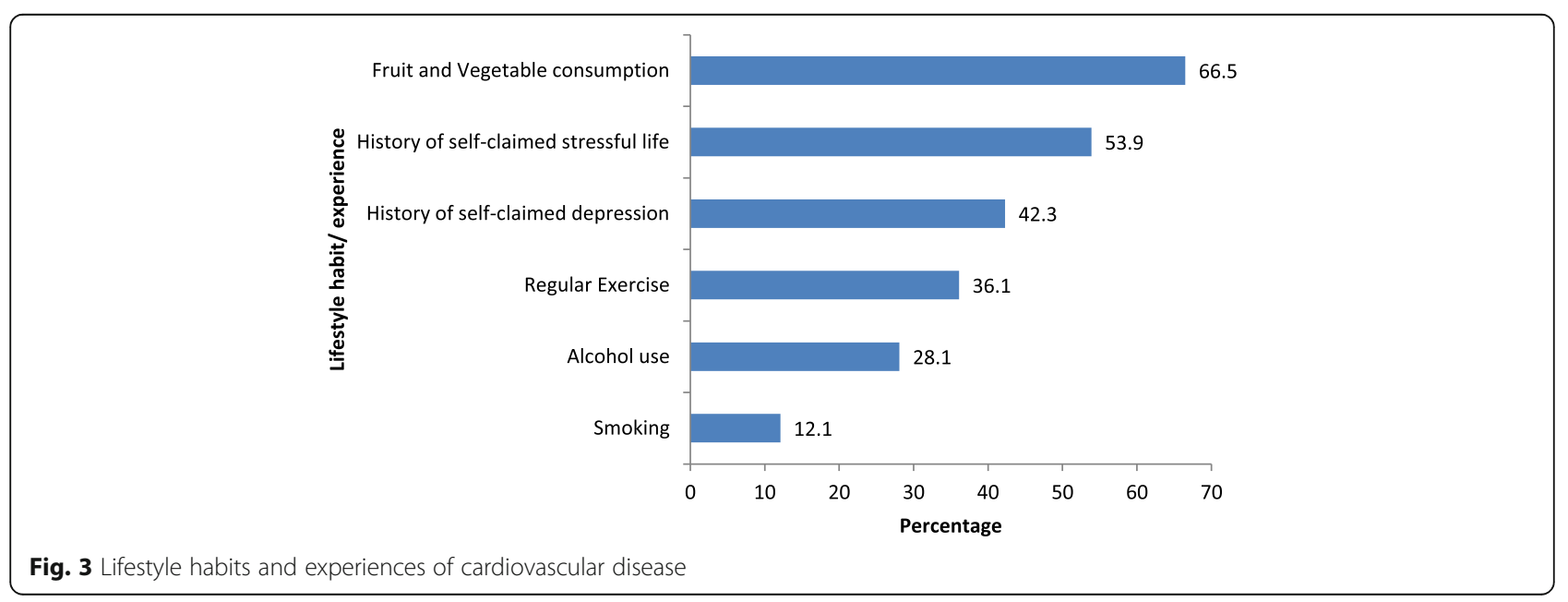




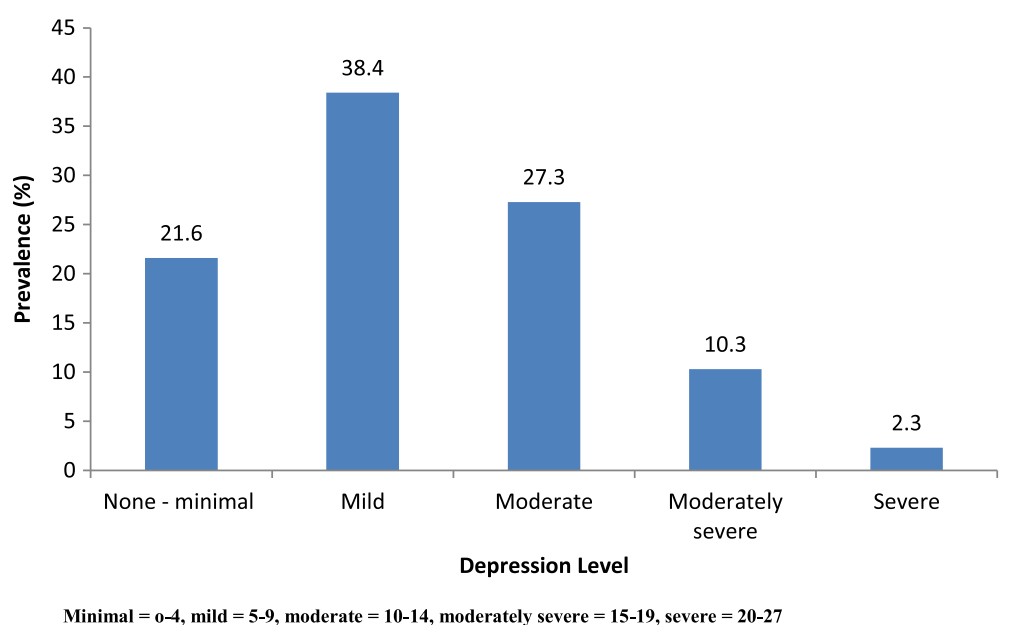

Fig. 4 Patients' Patient Health Questionnaire-9 depression category distribution

angioplasty $(72.4 \%, p=0.42)$, both of which were not significantly associated with depression (Table 2). This contradicts the findings of Chaudhury et al. who reported that before and after receiving percutaneous transluminal coronary angioplasty, $32.1 \%$ and $3.6 \%$ of patients respectfully had clinically significant depression [58]. This may relate to other interventions that may accompany surgical procedures such as counselling and cardiac rehabilitation. Cardiac rehabilitation in Trinidad and Tobago is absent in the public health institutes. Some studies have identified higher depression levels among patients who subsequently became unemployed [59] and those with income, relationship, and participation restrictions [60, 61]. The absence of association between depression and age, ethnicity, monthly income, or religious affiliation in this study is in line with findings of Munga who showed that age, sex, and marital and socioeconomic statuses did not significantly affect the development of depression in patients with cardiac diseases [62].

There was a high correlation between self-reported stress and the depression score obtained from the PHQ-9. Patients with self-reported depression were four times more likely to be depressed (PHQ-9 $>9$ ). There may be a case for treating those that self-report feelings of depression without elaborate screening for depression. However, this method may neglect cases of an occult nature that may be in greater need of assistance, since many of these patients may even be suicidal [63] and unwilling to share their feelings. Depression among patients with self-reported stress was twice as common as

Table 2 Odds ratios of associated factors and depression

\begin{tabular}{|c|c|c|c|c|}
\hline \multirow[b]{2}{*}{ Factors } & \multirow[b]{2}{*}{ OR } & \multirow[b]{2}{*}{$p$-value } & \multicolumn{2}{|c|}{ 95\% Confidence Interval } \\
\hline & & & Lower & Upper \\
\hline Sex (ref Female) & .548 & 0.015 & 0.336 & 0.894 \\
\hline${ }^{\mathrm{a}}$ Employment & .452 & 0.007 & 0.252 & 0.811 \\
\hline \multicolumn{5}{|l|}{ Comorbidity } \\
\hline${ }^{a}$ Hypertension & 2.063 & 0.017 & 1.129 & 3.767 \\
\hline \multicolumn{5}{|l|}{ Psychological } \\
\hline 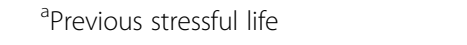 & 2.327 & 0.001 & 1.417 & 3.822 \\
\hline${ }^{a}$ Current stressful life & 2.943 & 0.001 & 1.771 & 4.892 \\
\hline 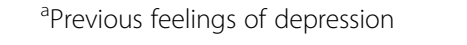 & 5.517 & 0.001 & 2.815 & 10.813 \\
\hline${ }^{a}$ Current feelings of depression & 6.724 & 0.001 & 3.432 & 13.175 \\
\hline a'Living alone & 2.992 & 0.006 & 1.316 & 6.798 \\
\hline \multicolumn{5}{|l|}{ Lifestyle } \\
\hline${ }^{a}$ Exercise 3 times per week for $>20$ min & 0.394 & 0.001 & 0.241 & 0.645 \\
\hline
\end{tabular}

CVD cardiovascular disease, IHD ischemic heart disease, CABG coronary artery bypass graft, TIA transient ischemic attack a reference values: unemployment, no hypertension, no previous stressful life, no current stressful life, no previous feelings of depression, no current feelings of depression, not living alone, and not exercising 3 time per week for $>20 \mathrm{~min}$ 
among those without self-reported stress. These findings are corroborated by Schrader et al. who showed that self-reported history of depression, anxiety, or stress [64] were useful predictors of mild or moderate to severe level of depressive symptoms at hospitalisation.

Social support, while not robustly examined, did not significantly impact depression prevalence in this study. This may be related to the high percentage (at least $80 \%$ ) of patients who had some form of support and is comparable to previous findings of $79.9 \%$ of patients receiving support from a spouse or relative [55]. Social support refers to the various types of support that people receive from others and is generally classified into two or three major categories: emotional, instrumental, and (sometimes) informational support [65]. Low social support infers that the emotional, instrumental, and informational assistance/help that people receive from others is lacking. Low social support is a robust risk factor for major depressive disorder [66]. Higher depression levels were also found in those living alone [67] or those who experienced social neglect at the work place [59]. Freidmann et al. found that depression and social isolation predicted mortality in heart failure patients [68].

A multitude of other factors such as those pertaining to personality may also be related to depression. Individuals with negative illness beliefs [69] and those with high neuroticism and low extraversion scores were found to be more vulnerable to depression [70] as was reported by a study conducted among older CHD patients. Living alone, alcohol abuse, perception of medical care as being a substantial economic burden, and health status were identified as predictors of developing depressive symptoms [71].

This study found that employment and exercising at least three times per week for 20 min provided additional protective benefits, since these patients were $50 \%$ less likely to develop depression compared to those who were unemployed or exercised less following MI [72]. In fact, regular exercise can be used as an instrument to reduce depression in patients after CAD events [73]. Similarly, another study reported increased levels of depression associated with adverse changes in employment after experiencing an MI [74].

\section{The way forward}

In this study, four patients or $1 \%$ reported receiving formal help from a psychiatrist or psychologist. This is despite at least $40.0 \%$ having clinical depression (moderate, moderately severe, or severe depression) based on PHQ-9 > 9. A large percentage of untreated patients has been reported in other studies; Smolderen et al. found that $528(69.6 \%)$ patients had untreated depression [44]. Because of the high incidence of disease complications and the increased mortality associated with depressed patients with cardiac disease $[3,5]$, patients with depression must be identified and treated in an appropriate manner e.g. with counselling, psychotherapy, and/or pharmacotherapy [75] to improve their quality of life.

\section{Limitations}

This was a single-centre study with non-debilitated patients with cardiac disease with a relatively small convenience sample. Convenience sampling has a degree of bias, although efforts were made to select all eligible patients during the study period. The exclusion of patients with severe health illnesses has led to underestimation of the prevalence of depression among patients with cardiac disease, since those with high disease severity may be more likely to be depressed. Conversely, there is a potential to spuriously inflate somatic symptoms after admission and thus, artificially inflate depression prevalence. Interviewing patients 3-5 days after admission may exclude some patients that had been discharged by that time. However, with an average length of stay of 5.6 days, most patients were available for interview. This study primarily depended on recall, which can be difficult for many patients. Certain questions may not have been sufficient to provide an adequate evaluation of variables such as social support, stress, or depression, since self-reports were used in the study. Though patients were willing to share their feelings, many responses could have been exaggerated or under-reported. The population was mainly Indo/Afro Trinidadian of lower socioeconomic status who sought support in the public healthcare system. Although generalisation would be difficult, this study produced findings that could be extrapolated to similar populations. Psychosocial issues such as divorce, suicide, unemployment, and crime, which may influence the extent and effect of depression in patients with cardiac disease, have not been addressed. Although the research assistants would inform the attending physician of patients with suicidal ideation, the patients were not identified, and no formal report could be conducted.

\section{Conclusion}

Depression was very common among patients with cardiac disease who presented most commonly with feelings of tiredness, insomnia, and inertia. Associated factors of depression included sex, employment, hypertension, previous and current stressful life, previous and current feelings of depression, living alone, and regular exercise. The OR for depression was the highest among patients who self-reported feeling stressed and depressed and among those living alone. Patients that regularly exercised and were employed were approximately 50\% less likely to have depression. Screening of all patients with cardiac disease is essential to identify and treat the patients at greater risk of depression. 


\section{Abbreviations}

CAD: Coronary artery disease; Cl: Confidence interval; CVD: Cardiovascular disease; IHD: Ischaemic heart disease; MI: Myocardial infarction; OR: Odds ratio; PHQ-9: Patient Health Questionnaire-9

\section{Acknowledgements}

I wish to acknowledge Dr. George Legall, statistician and lecturer at the University of the West Indies (Mt. Hope, Trinidad), who assisted with statistical analysis and methodology; Kristian Sookram and Kesley Rampersad, medical students, who assisted with data collection; the staff from the medical department, who helped with the research; and the participants, who gave their time to enter the study.

\section{Funding}

Not applicable.

\section{Availability of data and materials}

The data that support the findings of this study are available from the corresponding author on request.

\section{Authors' contributions}

MB conceptualised, designed, conducted, and reviewed the study; and wrote and revised the manuscript. The author read and approved the final manuscript.

\section{Author's information}

MB is a Specialist Medical Officer and lecturer at the School of Medicine and Arthur Lok Jack Graduate School of Business at the University of the West Indies (Mt. Hope, Trinidad).

\section{Ethics approval and consent to participate}

This study received ethical approval from the Ethics Committee of SouthWest Regional Health Authority. All participants gave their verbal consent to participate in the study.

\section{Consent for publication}

Not applicable.

\section{Competing interests}

The author declares no competing interests.

\section{Publisher's Note}

Springer Nature remains neutral with regard to jurisdictional claims in published maps and institutional affiliations.

Received: 14 March 2018 Accepted: 7 December 2018 Published online: 07 January 2019

\section{References}

1. Depression (major depressive disorder) - Symptoms and causes - Mayo Clinic. Mayoclinic.org. 2017 Available from: https://www.mayoclinic.org/ diseases-conditions/depression/symptoms-causes/syc-20356007 [Accessed 22 Dec 2017].

2. Murray CJ, Lopez AD. Evidence-based health policy--lessons from the global burden of disease study. Science 1996; 274:740-743. PubMed: 8966556 Available from: http://www.eurohex.eu/bibliography/pdf/0619262817/ Murray_1996_Science.pdf [Accessed 3 Feb 2018].

3. Depression. World Health Organization. Available from: http://www.who.int/ mediacentre/factsheets/fs369/en/ Accessed 22 Feb 2018].

4. Khayyam-Nekouei Z, Neshatdoost H, Yousefy A, Sadeghi M, Manshaee G. Psychological factors and coronary heart disease. ARYA Atheroscler 2013;9:102.

5. Khawaja IS, Westermeyer JJ, Gajwani P, Feinstein RE. Depression and coronary artery disease: the association, mechanisms, and therapeutic implications. Psychiatry (Edgemont). 2009;6:38-51.

6. Symptoms. nhs.uk. 2017. Available from: https://www.nhs.uk/conditions/ clinical-depression/symptoms/ Accessed 22 Dec 2017].

7. Tracy N. Effects of Depression: Physical, Social Effects of Depression - Effects - Depression. Healthy Place. 2017. Available from: https://www.healthyplace. com/depression/effects/effects-of-depression-physical-social-effects-ofdepression/\#ref; Accessed 22 Dec 2017.
8. Schmaal L, Veltman DJ, Van Erp TGM, Samann PG, Frodi T, Jahanshad N, et al. Subcortical brain alterations in major depressive disorder: findings from the ENIGMA Major Depressive Disorder working group. Mol Psychiatry. 2016;21:806-12. Available from: https://www.nature.com/articles/mp201569. pdf. Accessed 20 Dec 2018.

9. Kapfhammer HP. The relationship between depression, anxiety and heart disease - a psychosomatic challenge. Psychiatr Danub, Available from. 2011; 23:412-24 https://www.ncbi.nlm.nih.gov/pubmed/22075746 Accessed 22 Dec 2017.

10. Roshanaei-Moghadda, KWJ, Russo J. The longitudinal effects of depression on physical activity. Gen Hosp Psychiatr. 2009;31:306-315. doi: https://doi. org/10.1016/j.genhosppsych.2009.04.002. Epub 2009 May 13 Available from: https://www.ncbi.n/m.nih.gov/pubmed/19555789 Accessed 22 Dec 2017.

11. The inside story: The impact of depression on daily life. 2008. http://ec. europa.eu/health/ph_determinants/life_style/mental/docs/insidestory.pdf. Accessed 20 Dec 2018.

12. Kessler RC, Berglund P, Demler O, Jin R, Koretz D, Merikangas KR, et al. The epidemiology of major depressive disorder: results from the National Comorbidity Survey Replication (NCS-R). JAMA. 2003;289:3095-105.

13. Huffman JC, Celano CM, Beach SR, Motiwala SR, Januzzi JL. Depression and cardiac disease: epidemiology, mechanisms, and diagnosis. Cardiovasc Psychiatr Neurol. 2013. https://doi.org/10.1155/2013/695925.

14. May HT, Horne BD, Carlquist JF, Sheng X, Joy E, Catinella AP. Depression after coronary artery disease is associated with heart failure. J Am Coll Cardiol. 2009;53:1440-7.

15. Gomez J. Depression doubles long-term risk of death after heart disease diagnosis, intermountain study finds. Intermountain Healthcare. https:// intermountainhealthcare.org/news/2017/03/depression-doubles-long-termrisk-of-death-after-heart-disease-diagnosis/. Accessed 24 Aug 2017.

16. May HT, Horne B, Knight S, Knowlton KU, Bair TL, Lappé DL, et al. The association of depression at any time to the risk of death following coronary artery disease diagnosis: the intermountain inspire registry. J Am Coll Cardiol. 2017;69:57.

17. Hare D, Toukhsati S, Johansson P, Jaarsma T. Depression and cardiovascular disease: a clinical review. Eur Heart J. 2017;35:1365-72.

18. Yusuf S, Hawken S, Ôunpuu S, Dans T, Avezum A, Lanas F, et al. Effect of potentially modifiable risk factors associated with myocardial infarction in 52 countries (the INTERHEART study): case-control study. Lancet. 2004;364: 937-52.

19. Low CA, Thurston RC, Matthews KA. Psychosocial factors in the development of heart disease in women: current research and future directions. Psychosom Med 2010;72: 842-854. doi:https://doi.org/10.1097/ PSY.0b013e3181f6934f. Available from: https://www.ncbi.nlm.nih.gov/pmc/ articles/PMC2978285/pdf/nihms237360.pdf Accessed 22 Dec 2017.

20. Freeman A, Tyrovolas S, Koyanagi A, Chatterji S, Leonardi M, Ayuso-Mateos $\mathrm{L}$, et al. The role of socio-economic status in depression: results from the COURAGE (aging survey in Europe) BMC Public Health. 2016;16:1098. https://doi.org/10.1186/s12889-016-3638-0 Available from https://www.ncbi. nlm.nih.gov/pubmed/27760538 Accessed 30 Apr 2018.

21. Trinidad \& Tobago Crime Statistics. (n.d.). Available from: http://www. ttcrime.com/stats.php Accessed 29 January 2018.

22. Police Service reveal worrying statistics- Rape cases on the decline, but more sexual offences | The Trinidad Guardian Newspaper. (n.d.). Available from: http://www.guardian.co.tt/news/2014-12-13/police-service-reveal-worryingstatistics-rape-cases-decline-more-sexual-offences Accessed 29 Jan 2018.

23. Suicide mortality rate (per 100,000 population) | Data.(n.d.). Available from http://data.worldbank.org/indicator/SH.STA.SUIC.P5?locations= $=$ T\&view= chart Accessed 29 Jan 2018.

24. Julien, J. Divorce rate down. Trinidad Express.2015 September 17. https:// www.trinidadexpress.com/search/?|=25\&sd=desc\&s=start_time\&f=html\&t= article\%2Cvideo\%2Cyoutube\%2Ccollection\&app=editorial $\& q=$ Julien\%2FDivorce+rate+down.+. Accessed 20 Dec 2018.

25. World Development Indicators | DataBank. (n.d.). Available from: http:// databank.worldbank.org/data/reports.aspx? source=2\&country=TTO. Accessed 20 Dec 2018.

26. Hance M, Carney RM, Freedland KE, Skala J. Depression in patients with coronary heart disease, a 12-month follow-up. Gen Hosp Psychiatry. 1996;18:61-5.

27. Coronary heart disease in Trinidad and Tobago. World Life Expectancy. 2017. http://www.worldlifeexpectancy.com/trinidad-tobago-coronary-heartdisease. Accessed 16 Sept 2018. 
28. Gersh BJ, Sliwa K, Mayosi BM, Yusuf S. The epidemic of cardiovascular disease in the developing world: global implications. European Heart J. 2010;31:642-8.

29. Maharaj RG. Depression and the nature of Trinidadian family practice: a cross-sectional study. BMC Fam Pract. 2007;8:25.

30. Maharaj RG, Reid SD, Misir A, Simeon DT. Depression and its associated factors among patients attending chronic disease clinics in Southwest Trinidad. West Indian Med J. 2005;54:369-74.

31. Maharajh HD, Ali A, Konings M. Adolescent depression in Trinidad and Tobago. Eur Child Adolesc Psychiatry. 2006;15:30-7.

32. Frederick F, Maharajh $\mathrm{H}$. Prevalence of depression in type 2 diabetic patients in Trinidad and Tobago. West Indian Med J. 2013;62:628-31.

33. South West Regional Health Authority (SWRHA). Utilisation Report of the Medical Records Department. Port of Spain: Ministry of Health; 2016.

34. Hanwella R, Ekanayake S, de Silva VA. The validity and reliability of the Sinhala translation of the patient health questionnaire (PHQ-9) and PHQ-2 screener. Depress Res Treat. 2014;2014. https://doi.org/10.1155/2014/768978.

35. Hamo CE, Heitner JF, Pfeffer MA, Kim HY, Kenwood CT, Assmann SF. Baseline distribution of participants with depression and impaired quality of life in the treatment of preserved cardiac function heart failure with an aldosterone antagonist trial. Circ Heart Fail. 2015;8:268-77.

36. Haddad M, Walters P, Phillips R, Tsakok J, Williams P, Mann A, et al. Detecting depression in patients with coronary heart disease: a diagnostic evaluation of the PHQ-9 and HADS-D in primary care, findings from the UPBEAT-UK study. PLoS One. 2013:8:e78493.

37. Kroenke K, Spitzer R, Williams J. The PHQ-9 validity of a brief depression severity measure. J Gen Intern Med, Available from. 2001;16:606-13 https:// www.ncbi.nlm.nih.gov/pubmed/11556941 Accessed 5 Jan 2018.

38. Geddes MS. Depression detection in hospitalized cardiac patients. Graduate Theses Dissertations. 2010;630 https://digitalcommons.usu.edu/etd/630. Accessed 17 Nov 2018.

39. Schmidt $\mathrm{CO}$, Kohlmann T. When to use the odds ratio or the relative risk? Int J Public Health 2008;53:165-167. 1661-8556/08/030165-3 DOl: https://doi. org/10.1007/s000-00-7068-3.

40. Nunnally J, Bernstein L. Psychometric theory. New York: McGraw-Hill. 1978. Ref obtained from Cronbach's Alpha: A Tool for Assessing the Reliability of Scales Available from https://www.joe.org/joe/1999april/tt3.php/06/index. php Accessed 17 Nov 2018.

41. Al-Abbudi SJ, Lami FH, Wady ZA. Prevalence and assessment of severity of depression among ischemic heart disease patients attending outpatient cardiology department Baghdad teaching hospital, Baghdad, Iraq J Psychiatry 2017;21:2 DOI: https://doi.org/10.4172/2378-5756. 1000438 Available from: https://www.omicsonline.org/open-access/ prevalence-and-assessment-of-severity-of-depression-among-ischemicheartdisease-patients-attending-outpatient-cardiology-departmen-23785756-1000438.pdf Accessed 20 Dec 2018.

42. Suzuki T, Shiga T, Kuwahara K, Kobayashi S, Suzuki S, Nishimura K, et al. Depression and outcomes in hospitalized Japanese patients with cardiovascular disease. Circulation 2011;75. Available from: https://www. jstage.jst.go.jp/article/circj/75/10/75_CJ-11-0140/_pdf Accessed 3 Jan 2017

43. Lichtman JH, Bigger JT Jr, Blumenthal JA, Frasure-Smith N, Kaufmann PG, Lespérance $F$, et al. Depression and coronary heart disease: recommendations for screening, referral, and treatment: A science advisory from the American Heart Association Prevention Committee of the Council on Cardiovascular Nursing, Council on Clinical Cardiology, Council on Epidemiology and Prevention, and Interdisciplinary Council on Quality of Care and Outcomes Research: Endorsed by the American Psychiatric Association. Circulation. 2008;118:1768-75.

44. Smolderen KG, Buchanan DM, Gosch K, Whooley MA, Chan PS, Vaccarino V. Depression treatment and 1-year mortality following acute myocardial infarction: insights from the TRIUMPH registry. Circulation. 2017;135:16811689. doi.https://doi.org/10.1161/CIRCULATIONAHA.116.025140 Available from: http://circ.ahajournals.org/content/early/2017/02/16/ CIRCULATIONAHA.116.025140 Accessed 5 Jan 2018.

45. Polikandrioti M, Goudevenos J, Michalis LK, Koutelekos J, Kyristi H, Tzialas D, Elisaf M. Factors associated with depression and anxiety of hospitalized patients with heart failure. Hellenic J Cardiol. 2015;56:26-35. Available from: https://www.ncbi.nlm.nih.gov/pubmed/25701969 Accessed 8 Jan 2018.

46. Smolderen KG, Strait KM, Dreyer RP, D'Onofrio G, Zhou S, Lichtman JH, Geda $\mathrm{M}$, Bueno $\mathrm{H}$, Beltrame J, et al. Depressive symptoms in younger women and men with acute myocardial infarction: insights from the VIRGO study. J Am
Heart Assoc 2015;4:e001424 doi: https://doi.org/10.1161/JAHA.114.001424 Available from: https://www.ncbi.nlm.nih.gov/pmc/articles/PMC4579927/ pdf/jah3-4-e001424.pdf Accessed 5 Jan 2018.

47. Strik JJ, Lousberg R, Cheriex EC, Honig A. One year cumulative incidence of depression following myocardial infarction and impact on cardiac outcome. J Psychosom Res. 2004;56:59-66. Available from: https://www.ncbi.nlm.nih. gov/pubmed/14987965 Accessed 23 Dec 2017.

48. Romanelli J, Fauerbach JA, Bush DE, Ziegelstein RC. The significance of depression in older patients after myocardial infarction. J Am Geriatr Soc. 2002;50:817-822. Available from: https://www.ncbi.nlm.nih.gov/pubmed/ 12028166 Accessed 23 Dec 2017.

49. Rohyans LM, Pressler SJ. Depressive symptoms and heart failure: examining the sociodemographic variables. Clin Nurse Spec 2009;23:138-144. doi: https://doi.org/10.1097/NUR.0b013e3181a443b4. Available from: https:// www.ncbi.nlm.nih.gov/pmc/articles/PMC2743874/pdf/nihms106111.pdf Accessed 5 Jan 2018.

50. Whooley $\mathrm{M}$, de Jonge $\mathrm{P}$, Vittinghoff $\mathrm{E}$. Depressive symptoms, health behaviors, and risk of cardiovascular events in patients with coronary heart disease. JAMA. 2008:300:2379-88.

51. Celano CM, Huffman JC. Depression and cardiac disease: a review. Cardiol Rev. 2011;19:130-42

52. Huffman, JC, Celano, CM, Beach, SR, Motiwala SR, and Januzzi JL, CardiovasC Psychiatry Neurol. 2013; 2013: 695925. Published online 2013 Apr 7. doi: https://doi.org/10.1155/2013/695925.

53. Wilson-Genderson M, Heid AR, Pruchno R. Onset of multiple chronic conditions and depressive symptoms: a life events perspective. Innov Aging. 2017;1. https://doi.org/10.1093/geroni/igx022 Available from: https://www. ncbi.n/m.nih.gov/pubmed/30480117 Accessed 20 Dec 2018.

54. Pruchno RA, Wilson-Genderson M, Heid AR. Multiple chronic condition combinations and depression in community-dwelling older adults. J Gerontol A Biol Sci Med Sci. 2016;71:910-915. doi: https://doi.org/10.1093/ gerona/glw025. Epub 2016 Mar 1. Available from: https://www.ncbi.nlm.nih. gov/pubmed/26933159 Accessed 8 Jan 2018.

55. Schleifer SJ, Macari-Hinson MM, Coyle DA, Slater WR, Kahn M, Gorlin R, et al. The nature and course of depression following myocardial infarction. Arch Intern Med. 1989;149:1785-1789. Available from: https://www.ncbi.nlm.nih. gov/pubmed/2788396 Accessed 23 Dec 2017.

56. Anderson RJ, Freedland KE, Clouse RE, Lustman PJ. The prevalence of comorbid depression in adults with diabetes: a meta-analysis. Diabetes Care 2001;24:1069-1078. Available from: https://www.ncbi.nlm.nih.gov/pubmed/ 11375373 Accessed 8 Jan 2018.

57. Al-Ghamdi AA. A high prevalence of depression among diabetic patients at a teaching hospital in Western Saudi Arabia. Neurosciences (Riyadh). 2004;9: 108-112. Available from: https://www.ncbi.nlm.nih.gov/pubmed/23377362 Accessed 8 Jan 2018

58. Chaudhury S, Srivastava K. Relation of depression, anxiety, and quality of life with outcome after percutaneous transluminal coronary angioplasty. Sci World J. 2013. https://doi.org/10.1155/2013/465979 Available from: https://www.hindawi.com/journals/tswj/2013/465979/ citations Accessed 8 Jan 2018.

59. Hasanović M, Čizmić A, Jašarević M. The course of depression following myocardial infarction and the impact of the social neglect on the recovery of the patient. J Neurol Stroke. 2017:6:00223. DOl: https://doi.org/10.15406/ jnsk.2017.06.00223 Available from http://medcraveonline.com/JNSKJJNSK-0600223.php Accessed 23 Dec 2017.

60. Shimizu Y, Suzuki M, Okumura H, Yamada S. Risk factors for onset of depression after heart failure hospitalization. J Cardiol 2014;64:37-42 Available from: http://www.sciencedirect.com/science/article/pii/ S0914508713003328 Accessed 22 Dec 2017.

61. Weissman MM, Bland R, Joyce PR, Newman S, Wells JE, Wittchen HU. Sex differences in rates of depression: cross national perspectives. J Affect Disord. 1993;29:77-84 Available from: https://www.ncbi.nlm.nih.gov/ pubmed/8300980 Accessed 22 Dec 2017

62. Munga EN. Prevalence of depression among cardiac patients at Kenyatta National Hospital Nairobi. Nairobi: University of Nairobi; 2012. http:// erepository.uonbi.ac.ke/handle/11295/6905. Accessed 10 Aug 2017

63. Oliffe $J$, Ogrodniczuk JS, Bottorff JL, Johnson JL, Hoyak K. "You feel like you can't live anymore": suicide from the perspectives of Canadian men who experience depression. Soc Sci Med. 2012;74:506-14.

64. Schrader G, Cheok F, Hordacre AL, Guiver N. Predictors of depression three months after cardiac hospitalization. Psychosom Med, Available 
from. 2004;66:514-20 https://www.ncbi.nlm.nih.gov/pubmed/15272096 Accessed 29 Jan 2018.

65. MacArthur Research Network on SES and Health[Internet]. https://macses. ucsf.edu/1 Accessed 20 Dec 2018.

66. Patten SB, Williams JV, Lavorato DH, Bulloch AG. Reciprocal effects of social support in major depression epidemiology. Clin Pract Epidemiol Ment Health. 2010;6:126-31.

67. Emily M. Bucholz EM, SS. Rathore, K Gosch, A Schoenfeld, PG. Jones, DM Buchanan, JA. Spertus, HM Krumholz. Effect of living alone on patient outcomes after hospitalization for acute myocardial infarction. Am J Cardiol 2011;108:943-948. doi:https://doi.org/10.1016/j.amjcard.2011.05.023 Available from: https://www.ncbi.nlm.nih.gov/pmc/articles/PMC3670597/pdf/nihms464647.pdf Accessed 23 Dec 2017.

68. Friedmann E, Thomas SA, Liu F, Morton PG, Chapa D, Gottlieb SS. Relationship of depression, anxiety, and social isolation to chronic heart failure outpatient mortality. Am Heart J. 2006;152:940.e1-8 Available from: https://www.ncbi.nlm.nih.gov/pubmed/17070164.

69. Stafford L, Berk M, Jackson HJ. Are illness perceptions about coronary artery diseases predictive of depression and quality of life outcomes? J Psychosom Res. 2009;66:211-20

70. Kikhavani $\mathrm{S}$, Taghinejad H. Personality factor as a predictor of depression score among depressed and CHD patients. J Clin Diagn Res. 2015;9:VC04-7.

71. Havranek EP, Spertus JA, Masoudi FA, Jones PG, Rumsfeld JS. Predictors of the onset of depressive symptoms in patients with heart failure. J Am Coll Cardiol 2004;44:2333-2338. Available from: https://core.ac.uk/ download/pdf/82342602.pdf Accessed 20 Dec 2018.

72. Ernstsen L, Rangul V, Nauman J, Nes BM, Dalen H, Krokstad S, et al. Protective Effect of Regular Physical Activity on Depression After Myocardial Infarction: The HUNT Study. Am J Med. 2016;129:82-8.e1. doi: https://doi. org/10.1016/j.amjmed Available from: https://www.ncbi.nlm.nih.gov/ pubmed/26302141 Accessed 16 January 2018.

73. Janzon E, Abidi T, Bahtsevani C. Can physical activity be used as a tool to reduce depression in patients after a cardiac event? What is the evidence? A systematic literature study. Scand J Psychol. 2015;56:175-81. https://doi. org/10.1111/sjop.12190. Available from https://www.ncbi.nlm.nih.gov/ pubmed/25756318 Accessed 16 Feb 2018

74. AHA 2017: Patients who stop working after acute myocardial infarction can suffer lower quality of life - DCRI. DCRI. 2018. Available from: https://www. dcri.org/aha-2017-employment-status/ Accessed 17 Feb 2018.

75. Katon WJ. Epidemiology and treatment of depression in patients with chronic medical illness. Dialogues Clin Neurosci. 2011;13:7-23.

Ready to submit your research? Choose BMC and benefit from:

- fast, convenient online submission

- thorough peer review by experienced researchers in your field

- rapid publication on acceptance

- support for research data, including large and complex data types

- gold Open Access which fosters wider collaboration and increased citations

- maximum visibility for your research: over $100 \mathrm{M}$ website views per year

At BMC, research is always in progress.

Learn more biomedcentral.com/submissions 